\title{
Kearifan Lokal dalam Lagu Ayam Den Lapeh Garapan Orkes Gumarang
}

\author{
Esy Maestro ${ }^{1}$, Fajry Sub'haan Syah Sinaga ${ }^{2}$ \\ ${ }^{1}$ Lecturer at Music Education Department, Languages and Arts Faculty, Universitas Negeri Padang \\ Prof. Dr. Hamka Air Tawar - Padang, West Sumatera. \\ ${ }^{2}$ Lecturer at Music Education Department, Languages and Arts Faculty, Universitas Negeri Padang \\ Prof. Dr. Hamka Air Tawar - Padang, West Sumatera. \\ esymaestro@fbs.unp.ac.id, fajry.sinaga@fbs.unp.ac.id
}

*Corresponding Author

Received: day month 201x, Revised: day month 201x, Accepted: day month 201x

Published online: day month 201x

\begin{abstract}
Penelitian ini dilatarbelakangi oleh lagu Ayam Den Lapeh karya Orkes Gumarang yang menjadi hits nasional pada era 50-an dan 60-an hingga merajai musik Pop Indonesia, Malaya dan Singapura. Lagu Ayam Den Lapeh bahkan pernah diangkat menjadi film cerita oleh studio film PESARI dan PERFINI milik Djmaludin Malik dan Usmar Ismail. Salah satu hal yang menarik adalah perpaduan antara alat musik populer dan alat musik tradisional Minangkabau dalam setiap karya yang digarap Orkes Gumarang, termasuk dalam penggarapan lagu Ayam Den Lapeh.

Penelitian ini bertujuan untuk menganalisis, menginterpretasikan, dan mendeskripsikan kandungan nilainilai kearifan lokal lagu Ayam Den Lapeh garapan Orkes Gumarang dalam kajian Etnomusikologi. Secara khusus penelitian ini ditargetkan dapat melahirkan analisis yang mendalam tentang kearifan lokal yang ada dalam lagu Ayam Den Lapeh, dilihat dari aspek kebahasaan, aspek musik, aspek psikologi dan aspek sosiokultural.
\end{abstract}

Keywords: Local Wisdom, Ayam Den Lapeh, Orkes Gumarang, Minangkabau Song.

\section{Introduction}

Lagu Ayam Den Lapeh garapan Orkes Gumarang menjadi hits nasional pada era 50-an dan 60-an, sehingga dapat merajai musik pop di Indonesia, Malaya, dan Singapura[1]. Perkembangan musik popular Minangkabau pada saat ini hanya berkembang di wilayah masyarakat Minangkabau saja, hal ini berbeda dengan karya Orkes Gumarang yang hampir seluruhnya menggunakan bahasa Minangkabau, namun dapat menyebar keluar wilayah Sumatera Barat. Hal tersebut terbukti dengan keberadaan lagu Ayam Den Lapeh yang menjadi music background dalam layar lebar dengan format hitam-putih dibawah sutradara Alm. Usmar Ismail dan menjadi lagu yang sangat popular di kalangan masyarakat Minangkabau maupun non-Minangkabau[2].

Orkes Gumarang adalah kelompok musik yang berasal dari Sumatera Barat bergenre musik populer yang terkenal pada era 50an dan 60an. Menurut Nawas dalam buku Memori Orkes Gumarang, penamaan "Gumarang" diambil dari nama seekor kuda yang gagah perkasa dalam sebuah legenda Minangkabau berjudul Kaba Cindua Mato. Orkes Gumarang memperoleh masa kejayaannya pada era kepemimpinan Asbon Majid pada bulan Mei 1955-1964.

Pada Tahun 1945, untuk pertama kalinya lagu-lagu milik Orkes Gumarang dikumandangkan melalui siaran RRI Pusat Jakarta, lagu-lagu berbahasa Minang dimainkan dengan alat musik moderen seperti piano, gitar elektrik, vibraphone, stringbass, dan alat perkusi lainnya[3]. Orkes Gumarang merupakan kelompok musik yang berhasil mempopulerkan lagu Minangkabau dengan menyisipkan kandungan nilai budaya Minangkabau dalam beberapa karyanya, baik dari syair lagu maupun penggunaan alat musik tradisional Minangkabau[4]. 
Esy Maestro; Fajry Sub'haan Syah Sinaga, Local Wisdom in The Song Ayam Den Lapeh Arranged by Orkes Gumarang

Kandungan nilai budaya dapat juga diartikan sebagai kearifan lokal yang dimiliki oleh masyarakat Minangkabau, khususnya yang terkandung dalam lagu Ayam Den Lapeh ciptaan H. Hamid. Kearifan lokal Minangkabau yang tim peneliti maksud adalah sumber daya alam, kreativitas, pengetahuan lokal, kesenian tradisional termasuk dendang dan alat musik tradisional yang mengandung nilai-nilai dan makna tertentu, sehingga dapat menentukan harkat dan martabat manusia dalam pembangunan peradaban masyarakatnya[5]. Adat Minangkabau didasarkan pada akal-budi (perpaduan antara pikiran dan perasaan untuk mempertimbangkan baik dan buruk mengacu pada alam takambang jadi guru, raso jo pareso (rasa/karsa dengan periksa/kontrol) yang menurut alua jo patuik (alur dan patut) akan melahirkan sikap dan tingkah laku yang baik dengan memperhatikan perasaan malu dan sopan, agar dapat memunculkan kearifan pengetahuan dan perilaku sebagai manusia dalam kehidupan sosial yang beradab.

Proses aktualisasi nilai kearifan lokal yang terkandung dalam adat-istiadat Minangkabau. Nilai tersebut dijadikan sebagai pedoman dalam melahirkan perilaku yang menggambarkan karakteristik Minangkabau. Barendregt mengatakan bahwa,

"Minangkabau songs, provides one of the avenues through which identification as Minangkabau is experienced, defined, and consumed internally. It constructs a Minangkabau sensibility "by depicting a recognizable landscape through the use of metaphors" related to migration and the homeland[6]."

Sama halnya dengan lagu Ayam Den Lapeh yang dapat mencerminkan kebudayaan Minangkabau yang didefinisikan, diyakini, dan dilakukan dalam kehidupan sehari-hari dapat membangun perasaan tentang kekayaan alam yang digambarkan dalam majas metafora terkait dengan kebudayaan Minangkabau dan tradisi yang ada di dalamnya. Lagu-lagu Minangkabau lebih dari sekedar menceritakan tentang kerinduan terhadap alam Minangkabau, bahkan merupakan upaya masyarakat untuk berbagi nilai-nilai moral dan pesan yang terkandung dalam penggunaan syair. Menurut Desyandri aspek-aspek yang dapat digunakan untuk melihat kebudayaan yang melekat dalam suatu kesenian, yaitu: (1) Aspek kebahasaan; (2) Aspek Musikalitas; (3) Aspek Psikologi; (4) Aspek Sosiokultural; (5) Aspek Pendidikan dan Nilai-nilai Edukatif[7]. Beberapa aspek tersebut akan digunakan untuk menganalisis kearifan lokal yang terkandung dalam lagu Ayam Den Lapeh garapan Orkes Gumarang.

Penelitian ini dirasa penting karena kearifan lokal merupakan unsur kebudayaan yang mengandung gagasan, pengetahuan, makna dan nilai, serta adat istiadat yang telah lama berkembang dalam suatu masyarakat. Pada kenyataannya, kearifan lokal di beberapa daerah sudah mulai pudar dan masyarakat tidak mampu menyaring kebudayaan yang berasal dari luar bahkan lebih sering mengikuti budaya yang berasal dari luar. Hal tersebut tidak berlaku pada Orkes Gumarang yang berhasil menggabungkan budaya dari luar dengan kearifan lokal Minangkabau dalam bentuk karya-karya musiknya, salah satunya adalah lagu Ayam Den Lapeh. Lagu ini bahkan dianggap oleh beberapa masyarakat bukan sebagai lagu daerah, tetapi lagu Indonesia yang berbahasa daerah[3]. Berdasarkan pengamatan terhadap data dan kenyataan di lapangan, termasuk penghayatan atas lirik lagu Ayam Den Lapeh, terdapat sejenis butir kearifan lokal yang memerlukan penelaahan dan pengkajian lebih mendalam.

\section{Related Works/Literature Review}

Artikel Dean Stales Yori dalam Jurnal Pendidikan Sejarah Vol 4, No 2 Tahun 2014 berjudul Orkes Gumarang: Pelopor Musik Minangkabau Modern Tahun 1953-1980, berisi tentang kiprah Orkes Gumarang sebagai pelopor musik populer Minangkabau Tahun 1553-1980. Beberapa bahasan dalam artikel tersebut sangat membantu terkait dengan informasi dan perkembangan Orkes Gumarang ketika membawakan lagu Ayam Den Lapeh.

Artikel Desyandri dalam Jurnal Komposisi Vol XVII, No 1 Tahun 2016 berjudul Interpretation The Educational Values Of Kambanglah Bungo Song For Student Character Building (A Hermeneutic Analysis), berisi tentang pembahasan nilai-nilai pendidikan yang terdapat dalam lagu Kambanglah Bungo. Beberapa bahasan dalam artikel tersebut sangat membantu dalam melihat kandungan nilai yang terkandung dalam lagu Ayam Den Lapeh karya Orkes Gumarang yang dilihat melalui aspek kebahasaan, aspek musik, aspek psikologis, dan aspek sosio-kultural. 
Esy Maestro; Fajry Sub'haan Syah Sinaga, Local Wisdom in The Song Ayam Den Lapeh Arranged by Orkes Gumarang

\section{Material \& Methodology}

\subsection{Data}

Penelitian ini terbagi menjadi dua tahap, yaitu tahap pertama adalah penelitian pendahuluan dan tahap kedua penelitian utama. Penelitian pendahuluan meliputi penentuan informan, pengumpulan data yang terkait dengan lagu Ayam Den Lapeh dan analisis tentang elemen musikal lagu Ayam Den Lapeh garapan Orkes Gumarang. Penelitian utama meliputi analisis deskriptif Kearifan Lokal yang terdapat dalam lagu Ayam Den Lapeh berdasarkan aspek kebahasaan, aspek musik, aspek psikologi dan aspek sosio-kultural. Sumber data tersebut dapat dicatat melalui catatan tertulis, pengambilan foto, rekaman suara, dan rekaman video. Terdapat tiga tindakan untuk mendapatkan informasi yang terkait, yaitu: observasi, wawancara dan studi pustaka. Studi pustaka dilakukan dengan cara menggunakan literatur buku-buku maupun berbagai referensi dari literatur lain seperti media cetak dan elektronik

\subsection{Method}

Penelitian ini bersifat deskriptif analitis. Metode ini dimaksudkan untuk mengkaji dan menganalisis nilai-nilai kearifan lokal yang terkandung dalam lagu Ayam Den Lapeh garapan Orkes Gumarang. Pendekatan utama dalam penelitian ini adalah Etnomusikologi. Etnomusikologi adalah sebuah studi musik tradisional yang dipelajari secara lisan atau turun-temurun dan tidak melalui tulisan. Pada umumnya musik tradisi diajarkan secara turun-temurun dari generasi sebelumnya, dan berkembang hingga saat ini. Karya-karya Orkes Gumarang dipopulerkan dengan cara dipentaskan secara langsung maupun hasil dari rekaman berupa piringan hitam maupun kanal Youtube.

\section{Results and Discussion}

\subsection{Perjalanan Musik Orkes Gumarang}

Orkes Gumarang terbentuk pada tahun 1953 yang dipelopori oleh beberapa putra Minang yang ada di Jakarta. Pertama kali terbentuk dibawah pimpinan Anwar Anief, setelah itu dipimpin oleh Alidir. Pada tahun 1955, Orkes Gumarang dibawah pimpinan Asbon lebih banyak dikenal diseluruh Nusantara, melalui siaran tetap di RRI Jakarta.

Pada tahun 1956 Orkes Gumarang memulai untuk merekam lagu-lagu Minang tradisional yang diaransir dengan baik dan modern disertai paduan suara yang harmonis. Rekaman melalui piringan hitam dilakukan di studio-studio musik seperti LOKANANTA, REMACO, MESRA, SUARA MAS, DEMITA, dan IRAMA. Piringan hitam menjadi media dalam menyebarkan lagu-lagu Minang modern keseluruh Indonesia bahkan sampai ke Malaysia. Orkes Gumarang tidak hanya disenangi oleh kalangan Minang saja, banyak sekali permintaan untuk memeriahkan resepsi-resepsi kantor pemerintah, Perusahaan Swasta, Kedutaan Asing dan pesta-pesta besar perkawinan yang bukan orang Minang[3].

Tahun 1960 Orkes Gumarang mulai mengadakan pertunjukan di kota-kota besar di Indonesia, mulai dari Sumatera, Aceh, Jawa dan Bali. Dalam pementasan disetiap kota tersebut antusias penonton sangat besar, walaupun mereka tidak mengerti syair yang berbahasa Minang namun para penonton tidak ada yang beranjak sebelum pertunjukan benar-benar selesai.

Bulan Februari tahun 1964 beberapa pemain musik Orkes Gumarang (Asbon, Eddin Arifin, Juni Amir) mendapat tugas dari Negara untuk mengikuti Misi Kesenian Indonesia ke Amerika Serikat selama sebelas bulan untuk mengiringi tari-tarian daerah Sumatera dan Kalimantan dalam pekan raya dunia New York World Fair dan diteruskan ke Eropa. Tahun 1970, Orkes Gumarang kembali ditugaskan ke Pekan Raya Expo 1970 di Osaka Jepang selama sebelas bulan.

Setelah berkeliling Dunia dan Indonesia, pada tahun 1971 untuk pertama kalinya Orkes Gumarang mengadakan pertunjukan di Kota Padang. Para personil yang turut serta memeriahkan dalam pementasan di Kota Padang yaitu Nurseha, Syaiful Nawas, Dhira Suhud, Asbon, dan Anas Yusuf beserta istrinya Elly Kasim, diiringi musik dari Anggota Orkes Pancaragam Tentara Divisi Banteng Bukit Barisan[3].

Lagu-lagu yang telah dibawakan oleh Orkes Gumarang seluruhnya berbahasa Minang dan alat musik yang digunakan tidak lepas dari alat musik tradisional Minangkabau yang diaransir dengan sangat baik menjadi sebuah pertunjukan lagu-lagu Minang modern. Diantara lagu Orkes Gumarang 
Esy Maestro; Fajry Sub'haan Syah Sinaga, Local Wisdom in The Song Ayam Den Lapeh Arranged by Orkes Gumarang

hingga saat ini yang masih disenangi adalah lagu Laruik Sanjo dan Ayam Den Lapeh. Kedua judul lagu tersebut pernah diangkat menjadi film cerita oleh studi film PERSARI dan PERFINI milik Djamaludin Malik dan Usmar Ismael.

\subsection{Kandungan Nilai Kearifan Lokal dalam lagu Ayam Den Lapeh}

Kandungan nilai kearifan lokal yang terdapat dalam lagu Ayam Den Lapeh ciptaan Nurseha dan melodi Abdul Hamid, dapat dilihat melalui beberapa aspek yaitu aspek kebahasaan, aspek musikologis, aspek psikologis, dan aspek sosio-kultural[7].

\section{2. 1. Aspek Kebahasaan}

Syair dalam lagu Ayam Den Lapeh menggunakan bahasa Minang yang memiliki arti yang mendalam dalam setiap kalimat yang digunakannya. Berikut adalah syair lagu Ayam Den Lapeh dalam bahasa Minang dan juga terjemahannya dalam bahasa Indonesia.

\section{(bait pertama)}

Luruihlah jalan Payakumbuah

Babelok jalan Kayu Jati

Dima hati indak karusuah

Ayam den lapeh ai ai

Ayam den lapeh

\section{(bait kedua)}

Mandaki jalan Padangsikek

Basimpang jalan ka Biaro

Di ma hati indak maupek

Awak takicuah ai ai

Ayam den lapeh

\section{(bait ketiga)}

Sikucapang sikucapeh, saikua tabang saikua lapeh

Tabanglah juo nan karimbo

Oilah malang juo

\section{(bait keempat)}

Pagaruyuang Batusangka

Tampek bajalan urang baso

Duduak tamanuang tiok sabanta

Oi takana juo ai ai

Ayam den lapeh
Luruslah jalan ke Payakumbuh

Berbelok jalan ke Kayu Jati

Dimana hati tidaklah resah

Ayamku lepas, ai ai

Ayamku lepas

Mendaki jalan Pandai Sikek

Bersimpang jalan ke Biara

Dimana hati tidaklah kesal

Aku terkecoh, ai ai

Ayamku Lepas

Yang dikejar tak dapat

Yang sudah ada berlepasan (peribahasa)

Terbanglah jauh ke rimba

Oh malang sekali

Pagaruyung Batu Sangkar

Tempat berjalan orang baso

Duduk termenung sebentar

oohh terkenang lagi

Ayamku Lepas

Syair atau lirik lagu Ayam Den Lapeh berjenis pantun dalam puisi lama Minangkabau, jika ditinjau kembali syair lagu terdiri dari empat bait, dalam setiap bait berisi empat baris. Di antara bait tersebut ada yang memiliki baris tambahan yaitu Ayam Den Lapeh yang merupakan judul lagu. Terdapat tiga baris tambahan yang menggunakan kata seru "ai" seperti kata "aduhai".

Lagu Ayam Den Lapeh yang memiliki arti Ayamku Lepas merupakan lagu Minang yang mengisahkan tentang kehilangan. Jika dilihat dari sejarah orang Minagkabau terdahulu, ayam merupakan simbol sesuatu yang sangat berharga karena hanya orang tertentu yang mampu memeliharanya, sehinga tidak sembarang orang dapat memelihara ayam. Lagu ini secara keseluruhan dapat dianggap sebagai ekspresi perasaan kehilangan. Kehilangan akan barang berharga yang dikonotasikan dengan ayam. Lagu Ayam Den Lapeh merupakan pesan dan ekspresi dari penciptannya yang disampaikan melalui syair lagu tersebut[8].

Bait pertama dimulai dengan daerah-daerah yang ada di Sumatera Barat yaitu Payakumbuh dan kondisi jalan di Kayu Jati. Dalam lirik "di ma hati indak karusuah, ayam den lapeh" memiliki arti bagaimana hati tidak resah ketika ayam atau bisa berarti barang yang berharga sudah tidak ada lagi. 
Esy Maestro; Fajry Sub'haan Syah Sinaga, Local Wisdom in The Song Ayam Den Lapeh Arranged by Orkes Gumarang

Pembahasan bait kedua pada lirik "di ma hati indak maupek, awak takicuah ai ai, ayam den lapeh" memiliki arti (di mana hati tidak kesal, aku terkecoh ai ai, ayamku lepas), terdapat kekesalan dan kemarahan ketika ayam lepas karena dalam syair tersebut menggambarkan bahwa kesalahan telah terjadi sehingga ayam terlepas, karena pada awalnya "aku" tidak menyangka ayam tersebut akan terlepas. Dalam perumpamaan ayam lepas, sangat cocok ketika menggunakan kata "kesal". Pada kehidupan sesungguhnya, seekor ayam akan berontak ketika tidak dipegang dengan benar. Lain halnya ketika badan atau sayap dipegang erat dengan sedikit sentuhan di bagian kepala akan mendiamkan si ayam.

Lirik "sikucapang sikucapeh, saikua tabang saikua lapeh" pada bait ketiga merupakan peribahasa yang berisi nasihat untuk bersyukur tentang apa yang sudah dimiliki dan menjaganya jangan sampai hilang. "Tabanglah juo nan karimbo, oilah malang juo" yang berarti (terbanglah jauh ke dalam rimba, oh malang sekali) ayam yang berharga akhirnya kabur ke hutan dan tidak dapat didapatkan kembali. Tersirat pesan lewat penggunaan kata "aku" bisa jadi pencipta lagu memiliki pengalaman pribadi tentang ayam ataupun barang berharga miliknya yang hilang. Dalam konteks saat ini, ayam tidak lagi termasuk dalam barang yang bernilai tinggi, namun tetap saja kehilangan ayam peliharaan ataupun ayam untuk dijadikan santapan lezat, tetap saja membuat kesal pemiliknya.

Bait keempat merupakan akhir dari lagu Ayam Den Lapeh yang memiliki lirik "duduak tamanuang tiok sabanta, oi takana juo ai ai" yang berarti (duduk termenung tiap sebentar, oi terkenang lagi). Pesan yang terkandung dalam bait keempat adalah ketika kita sudah benar-benar kehilangan dan tidak ada lagi yang dapat dilakukan, maka berusahalah untuk mengikhlaskannya walaupun dalam hati berkali-kali mengatakan "ya sudahlah", namun tetap saja terkenang kembali.

Pada aspek kebahasaan jelas terlihat pada syair ataupun lirik dalam lagu Ayam Den Lapeh menggunakan bahasa Minang yang dapat dikategorikan pantun dalam puisi lama Minangkabau. Terdapat pesan yang terkandung tentang kehilangan dan perasaan kesal maupun kecewa, namun terlepas dari itu pesan yang ingin disampaikan janganlah kita terlalu larut dalam perasaan tersebut, kita harus bangkit dan terus berusaha kembali jika mengalami hal yang tidak sesuai dengan harapan. Makna yang terkandung dalam syair lagu Ayam Den Lapeh sangat bertolak belakang dengan irama lagu yang terkesan riang. Selanjutnya akan dikaji lagu Ayam Den Lapeh pada aspek musikologi.

\section{2. 2. Aspek Musikologi}

Skala nada yang digunakan dalam lagu Ayam Den Lapeh menggunakan a minor natural pada ambitus a $-\mathrm{b}-\mathrm{c}^{1}-\mathrm{d}^{1}-\mathrm{e}^{1}-\mathrm{f}^{1}-\mathrm{g}^{1}-\mathrm{a}^{1}$. Karakter melodi yang digunakan memiliki sifat syllabic yaitu penggunaan satu nada untuk mewakili satu suku kata[9], hal tersebut dapat dilihat dalam notasi berikut.

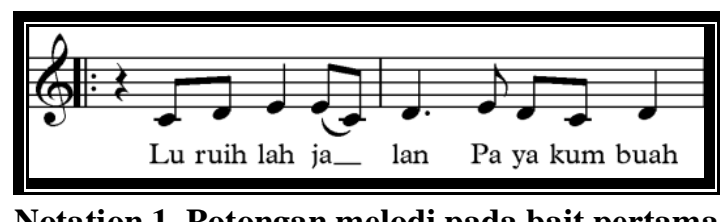

Notation 1. Potongan melodi pada bait pertama transcribed by: Fajry Sinaga, 2018

Frase melodi yang digunakan pada bait pertama adalah $a$ dan $b$, pada setiap akhir kalimat melodi selalu terdapat pengulangan subfrase yang bersifat menegaskan akhir perjalanan melodi pada suatu kalimat. Penegasan tersebut sama halnya dengan petuah-petuah di dalam dendang tradisi Minangkabau yang selalu menggunakan pengulangan pada akhir kalimat untuk menegaskan isi dari petuah atau cerita yang terkandung di dalamnya. Pengulangan melodi dalam lagu Ayam Den Lapeh terdapat pada akhir kalimat lagu yang tertera dalam potongan melodi berikut: 


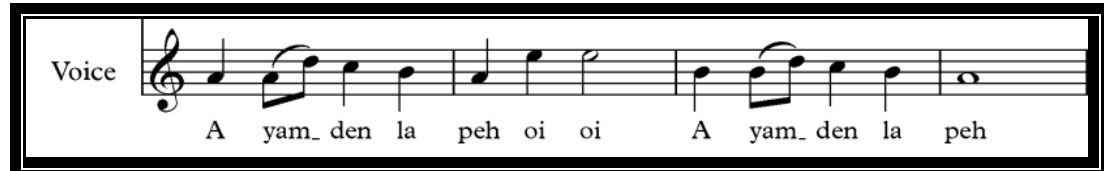

Notation 2. Salah satu bentuk pengulangan motif dalam lagu Ayam Den Lapeh transcribed by: Fajry Sinaga, 2018

Lagu Ayam Den Lapeh dibawakan dengan formasi musik modern dan dinyanyikan oleh penyanyi wanita ditambah perpaduan vocal group atau koor. Alat musik yang digunakan oleh Orkes Gumarang terdiri dari gitar, piano, konga, bongo, dan string bass. Konga dan Bongo menjadi alat musik yang sangat mendominasi dan berfungsi sebagai rhythm section. Style musik yang digunakan dalam lagu Ayam Den Lapeh adalah cha-cha-cha.

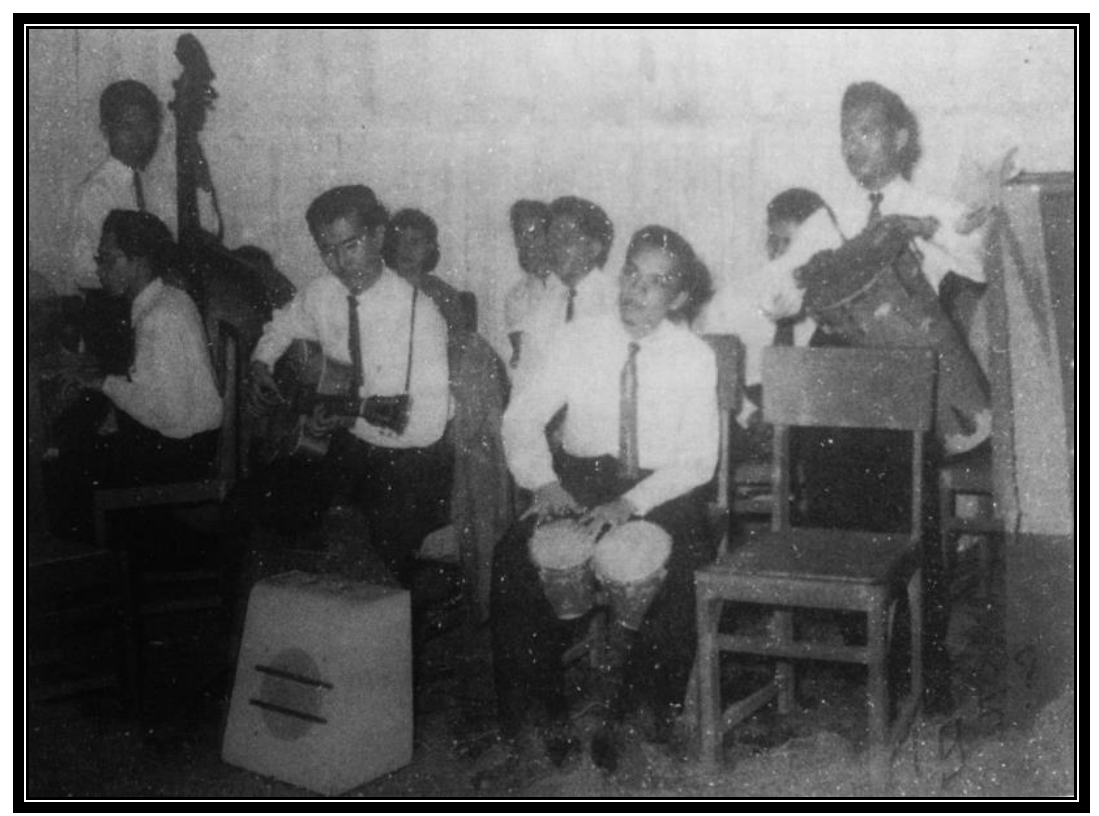

Figure 1. Orkes Gumarang bermain menggunakan alat musik perkusi buatan sendiri seperti konga, bongo, dll. source: Asbon, 1955/1965

Gaya cha-cha-cha merupakan pengembangan dari Mambo yang berasal dari tari suku Haiti yang tersebar melalui Kuba ke Amerika Serikat sekitar akhir 1940-an. Mambo memiliki tiga bentuk gaya yaitu single, double, dan triple. Gaya triple merupakan awal mula terbentuknya nama cha-chacha yang merupakan Onomatopoeia yang diimitasi dari bunyi sepatu wanita ketika menari gerakan tiga langkah[10]. Irama cha-cha-cha dalam lagu Ayam Den Lapeh yang diaransemen oleh Orkes Gumarang lebih dominan dimainkan oleh alat musik perkusi berupa konga dan bongo. Pola permainan perkusi cha-cha-cha dalam lagu Ayam Den Lapeh dapat dilihat dalam pola iringan berikut:

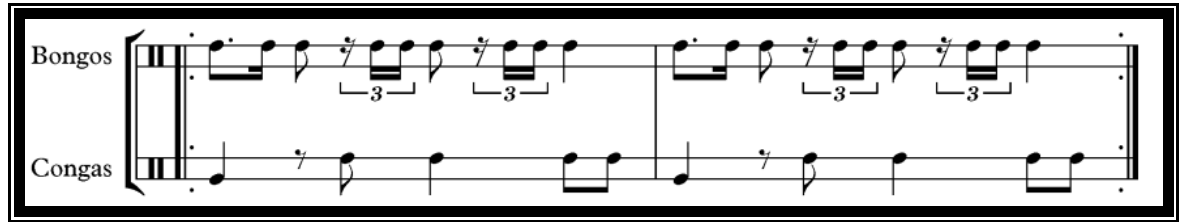

Notation 3. Pola iringan cha-cha-cha dalam lagu Ayam Den Lapeh transcribed by: Fajry Sinaga, 2018 
Esy Maestro; Fajry Sub'haan Syah Sinaga, Local Wisdom in The Song Ayam Den Lapeh Arranged by Orkes Gumarang

\section{2. 3. Aspek Psikologi}

Pesan yang terkandung dalam lagu Ayam Den Lapeh menyiratkan agar manusia tetap berusaha tegar, konsisten, dan kuat menjalani segala macam pengharapan walaupun belum tercapai. Kenyataan ini dapat dilihat pada pembahasan aspek kebahasaan dan aspek musikologi yang paradoksal antara kandungan pesan pada lagu Ayam Den Lapeh dan pemilihan style yang dipilih oleh Orkes Gumarang. Hal ini yang membuat lagu ini menarik, trend, populer pada masanya.

Masyakat yang menikmati lagu Ayam Den Lapeh tidak lagi melihat kandungan pesan atau isi dari lagu tersebut, baik yang mengerti bahasa Minang maupun tidak. Lagu Ayam Den Lapeh lebih identik dengan lagu yang bahagia karena menggunakan irama cha-cha-cha yang biasa digunakan untuk menari cha-cha.

\section{2. 4. Aspek Sosiokultural}

Lagu dimulai dengan nama-nama daerah yang ada di Sumatera Barat, seperti Batusangkar dan Pagaruyuang. Banyak pesan yang lain yang terkandung dalam lagu Ayam Den Lapeh salah satunya sesuai dengan kebiasaan orang Minang yaitu hidup merantau. Merantau mengajarkan kepada masyarakat Minang jangan hanya berdiam diri di kampung saja, karena bagi suku Minang yang bukan disebut rantau hanyalah di Nagari Pariangan, diluar nagari itu disebut daerah rantau. Lagu Ayam Den Lapeh bercerita juga tentang susahnya mendapatkan ayam (harta) karena tidak fokus terhadap tujuan yang sudah direncakan ketika merantau. Karena tidak fokus ketika merantau sehingga harta yang seharusnya sudah didapatkan ternyata hilang dan tidak dapat dimiliki kembali.

Kesenian yang lahir dan hidup bersama masyarakatnya memiliki ciri khasnnya masingmasing yang dipengaruhi oleh iklim, kebudayaan, adat istiadat, mata pencaharian, bahkan kepercayaan yang ada di daerah tersebut[11]. Lagu yang berasal dari daerah pada umumnya menggunakan bahasa dari daerah tersebut, selain itu ide-ide dalam pembuatan lagu pasti terinspirasi dari kehidupan masyarakat dan alam sekitar[12]. Hal tersebut dapat ditemukan dalam lagu Ayam Den Lapeh yang mengangkat beberapa tempat di Sumatera Barat, salah satunya Batusangkar, Payakumbuah, pagaruyuang, orang baso, padangsikek, biaro, dan peribahasa minang yang terdapat dalam bait ketiga.

\section{Conclusion}

Berdasarkan pembahasan lagu Ayam Den Lapeh yang dilihat dari aspek kebahasaan, aspek musikologi, aspek psikologi, dan aspek sosiokultural terdapat butir-butir kearifan lokal Minangkabau yang memiliki kaitan dengan kehidupan masyrakat Minangkabau. Dilihat dalam aspek kebahasaan, lagu Ayam Den Lapeh merupakan lagu yang berbahasa Minangkabau yang berarti Ayamku Lepas. Lagu ini lebih mengangkat cerita kehilangan akan sesuatu yang berharga. Dalam filosofi kuno Minangkabau, ayam merupakan hewan yang berharga karena tidak semua orang dapat memiliki ayam sebagai peliharaan.

Aspek musikologi memberikan temuan yang paradok atau berbanding terbalik pada pembahasan aspek kebahasaan. Hal tersebut disebabkan pemilihan style cha-cha-cha dalam lagu Ayam Den Lapeh yang lebih berkesan riang dan gembira. Tidak sedikit masyakat yang menyukai lagu tersebut berasal dari luar daerah Minangkabau yang tidak mengerti apa maksud dan cerita dalam lagu Ayam Den Lapeh. Pembahasan Aspek Psikologi dalam lagu Ayam Den Lapeh memberikan nilai kearifan lokal yang sangat mendalam disamping lagu tersebut yang bercerita tentang kehilangan dan kesedihan namun penggunaan style iringan cha-cha-cha memberikan dampak supaya manusia harus terus berusahan dan semangat dalam mengahadapi pengaharapan yang tak kunjung datang.

Dalam aspek sosiokultural dapat juga dikaitkan dengan kebiasaan masyarakat Minangkabau yaitu merantau. Tujuan ketika merantau harus terus dijaga agar tidak menyimpang sehingga dapat menyebabkan harta yang seharusnya sudah dimiliki menjadi hilang. Hal tersebut sama halnya dengan lepasnnya ayam dalam lagu tersebut yang bisa saja karena kecerobohan dari pemiliknya.

Acknowledgement. This research is fully supported by Affiliation Research Grant. 


\section{References}

[1] D. S. Yori, “Orkes Gumarang : Pelopor Musik Minang Modern Tahun 19531980," Pendidikan Sejarah, vol. 4, no. 2, pp. 1-12, 2014.

[2] T. KS, "OM Gumarang dan Sekelumit Sejarah Musik Minang," Google Group, 2011. [Online]. Available: https://groups.google.com/forum/\#!topic/rantaunet/7OlrZs48Ag.

[3] A. Majid, Kumpulan Lagu Minang Modern Orkes Gumarang Pimp. Asbon M. Jakarta: Rora Karya, 1997.

[4] E. T. Putra, "Piringan Hitam dan Modernisasi Musik Minangkabau," Padang Ekspres, Padang, p. Budaya Cagak, 2015.

[5] N. A. Ridwan, "Landasan Keilmuan Kearifan Lokal,” Ibda`Jurnal Studi Islam dan Budaya, vol. 5, no. 1, pp. 27-38.

[6] B. Barendregt, “The Sound of'Longing for Home': Redefining a Sense of Community through Minang Popular Music," Bijdragen tot de Taal-, Land-en Volkenkunde, vol. 158, no. 3, pp. 411-450, 2002.

[7] Desyandri, "Interpretation The Educational Values of Kambanglah Bungo Song For Student Character Building (A Hermeneutic Analysis)," Komposisi, vol. VXII, no. 1, pp. 37-51, 2016.

[8] F. S. S. Sinaga, "Musik Trunthung Sebagai Media Ekspresi Masyarakat Warangan," Seminar Antar Bangsa, 2016. [Online]. Available: https://osf.io/preprints/inarxiv/wc4vy/.

[9] R. Johnson, D. Huron, and L. B. Collister, "Music and Lyrics Interactions and their Influence on Recognition of Sung Words: An Investigation of Word Frequency, Rhyme, Metric Stress, Vocal Timbre, Melisma, and Repetition Priming," Empirical Musicology Review, vol. 9, no. 1, pp. 2-20, 2014.

[10] C. C. Cha, G. Information, and M. Timing, "Introduction to Cha Cha Cha," 2001. [Online]. Available: http://icbda.com/tech-manual/introduction_ch.pdf.

[11] D. Desfiarni and D. Darmawati, "UPAYA PELESTARIAN TARI PODANG DI KELURAHAN NAPAR NAGARI KOTO NAN GADANG KECAMATAN PAYAKUMBUH UTARA KOTA PAYAKUMBUH," Jurnal Sendratasik, vol. 2, no. 1, pp. 65-74, 2013.

[12] F. S. Syah, "KESENIAN THEK-THEK WALISONGO DI KELURAHAN TRITIH KULON KECAMATAN CILACAP UTARA KABUPATEN CILACAP: Kajian Tekstual (Bentuk Pertunjukan dan Komposisi Musikal)," JURNAL SENI MUSIK, vol. 2, no. 1, 2013. 
Esy Maestro; Fajry Sub'haan Syah Sinaga, Local Wisdom in The Song Ayam Den Lapeh Arranged by Orkes Gumarang

\section{Appendix}

Appendixes, if needed, appear after Reference. 